\title{
A framework to review performance measurement systems
}

\author{
Manoochehr Najmi \\ Graduate School of Management and Economics, Sharif University of Technology, Iran \\ John Rigas, Ip-Shing Fan \\ Department of Enterprise Integration, Cranfield University, United Kingdom
}

Keywords Performance measurement, Review, Performance Improvement

\begin{abstract}
This paper describes a structured review framework for managing business performance. The framework entails the review of both business performance, including the strategic relevance of the measures, as well as the efficiency and effectiveness of the performance measurement system itself. A range of approaches and tools are employed in the framework which features a review card providing a high level view of the review process, showing the different types of review perspectives and their interactions.
\end{abstract}

\section{Introduction}

Performance measurement systems (PMS) have been on top of the list of the research and business agenda over the last few years. Businesses realised the importance of a multidimensional and balanced performance measurement system as a tool that would enable them to drive the company forward. The shortcomings of traditional accounting performance measures have been well-documented in literature and include failing to convey effectively strategies and priorities within an organisation (Skinner, 1974; Maskell, 1991), encouraging short-termism (Johnson and Kaplan, 1987) and inflexibility to change (Richardson and Gordon, 1980). It is now widely accepted that the use of appropriately defined measures can ensure the strategic alignment of the organisation and communication of the strategy throughout the business. Taking the concept a bit further, Andersson et al. (1989), Eccles (1991), Lynch and Cross (1991) and Kaplan and Norton (1992) identified the weaknesses of traditional measurement systems because of their uni-dimensional and backward looking nature. This led to the development of innovative performance measurement frameworks such as the Balanced Scorecard (Kaplan and Norton, 1992) and the EFQM Excellence Model (EFQM, 2003) which viewed business performance through more than one perspective. Moreover, Dixon et al. (1990), Maskell (1991), amongst others identified that performance measurement had to be coherent with low level action taken within the business. This initiated the development of processes to implement performance measurement systems (Neely, 1996; Bittitci, 1997; Bourne, 1998). Consequently, the need emerged for developing a way of sustaining and maintaining these successful performance measurement system implementations. It became obvious that there is a need to effectively review these systems (Neely, 1996; Maskell, 1991; Dixon et al., 1990; Ghalayini and Noble, 1996; Neely et al., 2000; Medori and Steeple, 2000; Bititci and Turner, 2000). The questions arising from previous 
research in the area of the performance measurement system maintenance stages are the basis on which this paper was formed. This paper will establish the need to review performance measurement systems, and propose a framework that explains how the review process is performed, the people involved and their roles, the frequency of the review and further relevant considerations.

\section{Background}

Business performance is a dynamic quantity that is ever changing by nature. Consequently, all performance interactions (internal and external) must be accounted for when the system changes. This task alone requires a method that can accommodate such change and can facilitate that process in a structured way.

Bititci et al. (1997) support that a feedback mechanism is essential to enable the correct deployment of strategic and tactical objectives, and further state that there should be a structured framework to facilitate this flow of information to the decision making function of the company. Within ISO 9000:2000 (ISO, 2000) as shown in Figure 1 developing a method for measurement, analysis and improvement is an integral part of the system.

\section{“Take in Figure 1"}

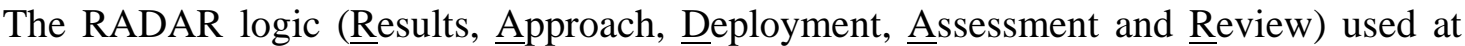
the heart of the EFQM Excellence Model (EFQM, 2003) includes the elements of assessment and review as part of its scoring methodology. The model is shown in Figure 2.

\section{“Take in Figure 2"}

According to the model, assessment and review covers what an organisation needs to review and improve both the approach and deployment of the approach for the main elements of an organisation which are known as enablers criteria. These criteria are leadership, policy \& strategy, people, partnership and resources, and processes. In an excellent organisation, the approach and deployment of it, will be subject to regular measurement, learning activities will be undertaken, and the output from both will be used to identify, prioritise, plan and implement improvement. The improvement in these criteria will be reflected in the organisational results which are customer, people, society and key performance results. Therefore, there is a cause and effect relationship between enablers and results. By using this approach, not only does the organisation help to review its performance, but also to use relevant measures to its business. BAE, the winner of the UK Business Excellence Award in 1999, has reported different levels of review in relation its policy and strategy as depicted in Figure 3 (BAE, 1999). It shows how low level reviews which tend to happen frequently have interaction with companywide review.

“Take in Figure 3” 
Wisner and Fawcett (1991), in their nine-step approach to designing a performance measurement system clearly state the need for periodic re-evaluation of the appropriateness of the established performance measurement system, but nevertheless do not provide enough information as to its deployment. Lingle and Schiemann (1996) suggest the inclusion of a periodical review process to a performance measurement system, reflecting possible changes to the competitive environment. Kueng et al (2001) empirically argue that many of the PMSs in place have not been developed systematically. They believe that two distinct cycles of "creation of PMS" and "use of PMS" should be distinguished. They clearly state that any PMS should be under review periodically and on the following circumstances one can go back from the second cycle to the first one:

- $\quad$ Business strategy is modified;

- $\quad$ Stakeholders state new requirements;

- $\quad$ Implemented performance indicators are not useful;

- $\quad$ New operational IT systems are put in place;

- $\quad$ New IT opportunities emerge.

This necessity for the maintenance of PMSs is also discussed in CMMI approach (CMMI, 2002) under one of the system requirements as "Establish and maintain the organisation's measurement repository". A similar argument has developed by Wettstein and Kueng (2002) using the Maturity Model for performance measurement systems. It has become evident in literature and in business that there is a need to review performance measurement systems in the ever-changing environment called modern markets. The main purpose of a structured review process is to help organisations be prepared for any adjustments required after the design and implementation stages of a performance measurement system. It is important not only to develop an effective and efficient means of reviewing the performance and performance measurement system of an organisation, but also a sustainable one, that will have the ability to adapt itself to the aforementioned "environmental" changes. The review process is an essential part of a successful development of performance measurement (Bourne et al, 2000) and is an element that can ensure the longevity and flexibility of the system.

\section{Application framework}

The review framework was part of a wider PMS design methodology that was developed and applied on two of the participating companies in the EU-funded project ${ }^{1}$.

The companies that the review framework approach was applied had used a generic performance measurement system (PMS) design approach consisting of three basic elements: Direction, Processes and Measures. The existence of the element of Direction implies that the company has defined its mission, vision and strategic objectives and that the company's direction is clear. Processes imply that the company is being managed by processes and is familiar with process improvement practises. Finally, Measures, implies

\footnotetext{
1 This paper was produced during the 28-month research project named: "Performance Measurement System for Total Quality Management" sponsored by the EC and funded under the ESPRIT initiative (TBP No. 26736). The participants were Business Integration Technologies (UK), ESADE Business School (Spain), Cranfield University (UK), Universitat Jaume I (Spain), Gres de Nules (Spain), Wendel Email (Germany).
} 
that the company has attached measures to its processes that have been derived from the strategy and reflect the company's direction. Their interactions as well as the different steps involved in each of the elements are depicted in Figure 4.

“Take in Figure 4"

It is important to mention that the parties involved in the definition of Direction, top level processes and strategic indicators are referred to as the Executive Team and the parties involved in the definition of the detailed processes and the operational indicators as the Process Team. The Process Owners are in charge of the Process Teams.

The approach can be applied to any company that is using the three elements shown in Figure 3 in one way or another.

\section{PMS review framework}

The framework was developed to facilitate the reviewing of business performance and performance measurement systems simultaneously and takes into account several key characteristics of the PMS design process and its associated measures presented in the literature (Neely et al., 2000) as shown in Table I. The table can be treated as checklist when the PMS and measures are being reviewed.

“Take in Table 1”

The overall framework for reviewing the PMS based on the action research is shown in Figure 5.

\section{“Take in Figure 5”}

The framework consists of two main review categories: Business performance and PMS performance. "Business performance" can have an impact on the PMS design and the PMS implementation. This review category assesses the performance of the business through the PMS, and for this purpose is divided into three levels based on their review frequency:

1. On-going, that deals with reviewing the operational performance of the business. The on-going review has an impact on the definition of the operational indicators (Measures).

2. Periodic, that deals with reviewing the strategic performance of the company by reviewing the strategic indicators. The periodic review has an impact on the definition of operational indicators as well as any additional process analysis that the company might want to carry out (process costing etc.) (Measures \& Processes)

3. Overall, which deals with the review of the company's overall strategic objectives, including the mission and vision statements of the business. The overall review has an impact on all steps of the Direction, Processes and Measures elements mentioned earlier (Direction \& Measures \& Processes). 
The second review category of the framework named "PMS performance", deals with the assessment of how efficient and effective the PMS is in actually measuring the company's performance. This also includes issues such as the accuracy of the mapping of the business onto the PMS and the efficiency of the PMS design process. Many of the tools which are explained at the next section of the paper, are being used by the companies participating in the EU research project. As a result, particular attention was placed at ensuring the usefulness and usability of the framework within an operating business context.

The three review sections are interrelated and provide inputs and outputs to each other. This ensures that none of the reviewing procedures are undertaken in isolation hence maintaining the functionality of the strategic alignment "backbone" of the PMS. To understand the interaction between the three different review categories a review card was developed illustrating the links. The card is depicted in Figure 3.

\section{“Take in Figure 6”}

The review card identifies the inputs and outputs to each of the review stages and how they interact together. It also brings the review process into perspective by defining the scope through each of the reviews is undertaken and the tools that can be used. Furthermore, it provides a suggested frequency as well as the type of people involved in the process to ensure maximum benefits. The purpose of the card is to provide constructive guidelines to the companies implementing the PMS review framework, so that they can understand the requirements and expected outputs of the process. The card provides a high level view of the review process from an operational point of view. This enables the company to understand not only the individual needs of each of the review stages but also the positioning of the review framework within the individual company's PMS.

The review framework and the review card comply with the findings of Bourne et al. (2000) through literature as stated below:

The performance measurement system requires developing and reviewing at a number of different levels as the situation changes. For example:

1) The performance measurement system should include an effective mechanism for reviewing and revising targets and standards.

2) The performance measurement system should include a process for developing individual measures as performance and circumstances change.

3) The performance measurement system should include a process for periodically reviewing and revising the complete set of measures in use. This should be done to coincide with changes in either the competitive environment or strategic direction.

4) The performance measurement system should be used to challenge the strategic assumptions. 


\section{Review procedure}

Within literature many of the tools mentioned have been used for process monitoring and control purposes and this is more evident amongst the quality field (Feigenbaum 1983; Ishikawa ,1991; Oakland, 1986). Nevertheless, they are not the only tools that can be used for process improvement and review purposes. Within each of the three main levels the framework provides information regarding the purpose of the specific review, the people involved (WHO), the tools used (HOW), and the expected output (WHAT). In the remainder of the paper the three main levels will be explained regarding their deployment and use within a PMS.

All review levels are of a similar layout:

1. Overview - where an explanation is given regarding the review's purpose and expected outputs and mechanisms, and steps are explained in more detail regarding the review's operational and functional requirements and

2. Support Tools - where possible set of tools that can be used to carry out such a review are suggested.

\section{On-going Review}

Overview

On-going review on a day to day basis is a practice that seeks to ensure that organisational processes are under control and are achieving the expected performance. The process team is usually responsible for this type of review and the results are reported back to the process owner. The on-going review deals mostly with operational indicators. Although the results of the review are reported back to the process owner, in order to solve possible problems or improve processes, the framework highly encourages the collaboration between different process owners. At this level the process owner can amend operational indicators, ensuring their alignment to strategic indicators. Any changes, even minor, will change the system (impact on the PMS design) and subsequently the implementation procedure in terms of data collection, IT considerations (if any), reporting and so on (impact on implementation).

The approach that can be applied to the on-going and periodic review is of the following generic nature:

1. Define the frequency, format and responsibility. The frequency of review, the format in which data are gathered and the person(s) who is/are responsible for this are identified.

2. Monitor and control the process. Once the required data gathered, it is monitored in a way showing whether the process is under control and moving towards the targets set for the indicators. If any adjustments are required, the approaches defined in the next steps will be helpful.

3. Diagnose. In this approach, one needs to identify the most critical aspects of the problem and to determine the root causes of the problem. 
4. Remedy. Once the root causes of the problems are identified, solutions should be proposed and implemented. Following that, it must be ensured that the solutions are effective and similar problems will not be created.

\section{Support Tools}

For an on-going review a number of tools and techniques for monitoring, controlling, investigating and problem solving are required. These can include:

- Seven basic tools (Cause and effect diagram, Run chart, Scatter diagram, Flow chart, Pareto chart, Histogram, Control chart)

- Seven management tools (Affinity diagram, Interrelationship digraph, Tree diagram, prioritisation grid, Matrix diagram, Process decision program chart, Activity network diagram)

- others

\section{Periodic Review}

\section{Overview}

In today's rapidly evolving and changing marketplace, flexibility is considered essential to the competitiveness of any organisation. To this end, it is important that a company possesses the ability to change its strategic orientation as times dictate. Therefore, the periodic review of its strategic indicators is crucial. This review will evaluate the overall performance of the organisation at the strategic level. One of the main inputs to this review process is information from the operational indicators level. This information is essential, if adjustments are needed to the strategic indicator level, since it can provide the platform for performing statistical and other relevant analyses. The main considerations for this review are:

- The effectiveness of the organisation in achieving its strategic objectives;

- The validity of any hypotheses regarding organisational performance developed during the design stages of the performance measurement system;

- The validity of possible relationship amongst performance indicators.

The Executive Team will be in charge for this kind of review. As mentioned before, the impact of any changes in measures should be considered in the PMS design and implementation accordingly. Due to the presence of the Executive Team, any elements of the generic PMS design approach (see Figure 3) can be altered. However, for most organisations changing the direction so frequently seems to be unlikely. Changing the organisational direction can be a fundamental change that may require re-design of the system. Therefore, if the organisation is doing well, only some amendments in measures and processes might be required.

The review of the strategic indicators may have a diverse impact on the PMS. In the executive team meeting (the same team that defines the strategic indicators) if it becomes obvious that the organisation fails to move effectively towards its strategic objectives then the causes should be analysed and might include: 
1. Under-performance at a lower level

2. Strategic objectives are not communicated effectively

3. Strategic objectives have not been defined properly

4. Validity/Relevance of the objectives

It is obvious that depending on the issue identified the course of action should be different for each individual case. The possibility of two or more cases being valid at the same time should not be excluded.

The validation of the hypotheses stated initially regarding possible performance indicator relationships, should be a driving force to the review process. If the study of data and information indicate a discrepancy in these hypotheses then the cause should be identified:

1. Was the method used to establish the hypotheses appropriate? (This may include review of the quality of data used and tools)

2. If there is no relationship, can that be proved?

3. Are any existing relationships relevant/contributing to the overall business?

The approach followed to address the above issues is similar to the on-going review.

\section{Support Tools}

The tools that may be used at this stage include the previously mentioned tools plus more specifically the following:

1. Trend analysis tools - Control Charts

2. Relationship analysis Tools - Correlation analysis, Multivariate analysis, Cause and effect diagrams, Pareto charts

3. Checking the consistency of the PMS communication - Departmental reports and input

\section{Overall Review}

Overview

This review tends to be in an annual basis in which the following considerations are taken into account:

- The validity of the mission and vision statements

- Whether the company's strategic objective still support the mission and vision of the organisation

Having this review on top of previous reviews will provide the organisation with the ability to be proactive in the real market rather than just a reactive. In other words, in this review all external and internal factors (SWOT analysis) will be considered to make any adjustment to the overall direction of the organisation. Also, the whole PMS system will be reviewed systematically to ensure its effectiveness and efficiency. Therefore, the PMS 
system can be updated as a result of change in the organisational direction or improving the system itself.

The approach followed for the overall review is as follows:

1. Arrange Review meetings. Due to the importance of this review, it is suggested that three milestones in terms of review meetings are to be arranged.

- Introductory meeting: In this meeting, the issues regarding scope, objectives and so on will be considered.

- Intermediate meeting: In this meeting, decisions about the adjustments required for the review process will be taken. Moreover, the diagnostic stage of the approach may have some reports for this meeting.

- Final meeting: In this meeting the proposal for actions based on remedial approach will be finalised.

2. Define the scope and objectives and resource allocation. According to the information gathered through periodic reviews and external factors such as new competitors, legislation, customer demands, etc., the scope and objectives of the review will be defined and appropriate resources will be allocated.

3. Diagnostic Approach. If the organisation suffered any problem at the organisational level, the root causes should be identified. The tools and techniques for overall review will help the organisation to do so.

4. Remedial approach. A proposal for the action to remove the problems and initiate improvement will be prepared.

\section{Support tools}

The tools used for the overall review of the PMS are larger scale review tools that affect the overall organisational direction and orientation. To this end they can be categorised as internal tools, i.e. tools that compare the organisational performance to a set standard of practise, and external tools, i.e. tools that concentrate on comparing the organisational performance to competitors and good or best-practice organisations. As an example, internal tools may include the process of Self-Assessment (EFQM, 2000) and external tools may include the process of benchmarking.

\section{Conclusions}

The performance measurement system of an organisation is the mechanism to manage and control the organisation. For organisations that use PMS as the basis for its operations and development, the health of the organisation depends on the effectiveness of the PMS. Maintaining the effectiveness of the organisation and the measurement systems requires a systematic review process. The process of reviewing performance is a complex task that spans the whole organisation. Involving the appropriate persons to spend sufficient time to review the PMS is a costly exercise. Nevertheless, it is very important to the continuous adjustment of the business and its performance orientation in today's markets. A good PMS review process seek the correct balance between the organisation benefits and the efforts required. 
This paper presents the process that was designed to review a PMS that have close integration of measures and business process. The work was completed with pilot applications in two European enterprises. Empirical work with the case enterprises in the implementation of the integrated PMS identified the review requirements. The review process proposed represents the balance of effects and efforts considered appropriate.

In the design of the review process, previous studies in PMS design and implementation were used as starting reference. In the integrated PMS, the top level measures (strategic) are systematically cascaded down to lower levels (operational). Therefore it is appropriate that in a systematic review, this link is maintained as part the PMS review. The review process is designed to consider both the organisational performance through the applied PMS and the validity of the PMS itself. To this end a set of tools and techniques that can be used is proposed. They detail the people, tool and expected output of each stage of the review process. The framework includes a set of possible questions and considerations that can be taken into account when reviewing performance measurement systems. A review card was developed to provide a view of the major elements at-a-glance.

Overall, the framework presented provides a structured way of performance review in a methodical and effective manner. This is useful for practitioners to apply and adapt in their situations. 


\section{References}

Andersson, P., Aronsson, H., Storhagen, N.G. (1989), "Measuring Logistics Performance”, Engineering Costs and Production Economics, Vol. 17, pp. 253-262.

BAE (1999), Submission for the UK Quality Awrad, BAE.

Bititci, U. S., Carrie, S.A., McDevitt L. (1997) ,"Integrated performance measurement systems: a development guide", International Journal of Production and Operations Management, Vol. 17, No. 5, pp. 522-534.

Bititci, U.S., Turner, T. (2000), "Dynamics of performance measurement systems”, International Journal of Operations and Production Management, Vol. 20, No. 6, pp. 692-704.

Bourne, M.C.S., (1999) "Designing and Implementing a Balanced performance Measurement System”, Control, July, pp.21-23.

Bourne, M., Mills, J., Wilcox, M., Neely, A., Platts, K. (2000), "Designing, implementing and updating performance measurement system”, International of Journal of Operations and Production Management, Vol. 20, No. 7, pp. 754-771.

Dixon, J. R., Nanni, J. and Vollmann (1990), The new Performance Challenge: Measuring Operations for World-Class Competition, Business One Irwin, Homewood, Illinois.

Eccles, R.G. and Pyburn, P.J (1992), "Creating a comprehensive system to measure performance”, Management Accounting, October , pp. 41-44.

Eccles, R.G. (1991), “The Performance Measurement Manifesto”, Harvard Business Review, January-February, pp. 131-137.

EFQM (2000), Self-Assessment based on the European Model for Total Quality, The European Foundation for Quality Management, Brussels.

EFQM (2003), The EFQM Excellence Model, The European Foundation for Quality Management, Brussels.

Feigenbaum, A. V. (1983), Total Quality Control, McGraw-Hill.

Fitzgerald, L. (1988), "Managing Performance Measurement in Service Industries”, International Journal of Operations \& Production Management, Vol 8, No 3, pp. 109-116.

Ghalayini, A.M., and Noble, J.S., (1996), “The changing basis of performance measurement", International Journal of Operations and Production Management”, Vol.16, No.8, pp63-80.

ISO (2000), ISO 9000:2000, International Organisation for Standardisation (ISO).

Ishikawa, K. (1991), Introduction to Quality Control, Chapman \& Hall.

Johnson, H.T. and Kaplan, R.S. (1987), Relevance Lost : The Rise and Fall of Management Accounting, Harvard Business School Press, Boston, MA.

Kaplan, R.S., and Norton D.P. (1992), "The Balanced Scorecard - Measures that drive performance”, Harvard Business Review, January/February, pp.71-79.

Kueng, P., Meier, A., Wettsrein, T. (2001), “ Performance Measurement Systems Must be Engineered", Communications of the AIS, Vol. 7, Article 3.

Lingle, J. H. and Schiemann, W. A., (1996) "From Balanced Scorecard to Strategic Gauges: Is

Measurement Worth it?’ Management Review, Vol. 85, No. 3, March, pp 56-62.

Lynch, R. L. and Cross, K. F. (1991), Measure Up - The Essential Guide to Measuring Business Performance, Mandarin, London..

Lynch, R. L. and Cross, K. F. (1992), Measure Up! Yard Sticks for Continuous Improvement, Blackwell Business.

Maskell, B.H. (1991), Performance Measurement for World Class Manufacturing: A Model for American Companies, Productivity Press, Cambridge, MA.

Medori, D. and Steeple, D. (2000), "A framework for auditing and enhancing performance measurement system”, International Journal of Operations and Production Management, Vol. 20, No. 5, pp 520-533.

Moseng, B. and Bredrup, H. (1993), "A methodology for industrial studies of productivity performance”, Production Planning and Control, Vol.4 No.3. 
Neely , A.D., Mills, J.F., Gregory, M.J., Richards, A.H., Platts, K.W., and Bourne, M.C.S. (1996), Getting the measure of your Business, Findlay, London.

Neely, A., Mills, J., Platts, K., Richards, H., Gregory, M., Bourne M., Kennerley, M., (2000), "Performance measurement system design: developing and testing a process-based approach", International Journal of Operations and Production Management, Vol. 20, No. 10, pp 11191145.

Oakland, J.S. (1986), Statistical Process Control - A Practical Guide, Heinemann.

Richardson, P. R. and Gordon, J. R. M., (1980), "Measuring Total Manufacturing Performance”, Sloan Management Review, Winter, pp47 - 58.

Senge, P.M. (1990), The Fifth Discipline: The Art and practice of the Learning Organization, Century, London.

Sink, D.S. and Tuttle, T. (1989), Planning and measurement in your organisation of the Future, Industrial Engineering and Management Press, Norcross, GA.

Skinner, W. (1974) "The decline, fall and renewal of manufacturing”, Industrial Engineering, October, pp.32-38

Stoop, P.P.M. (1996), Performance Management in manufacturing - a method for short term evaluation and diagnosis, $\mathrm{PhD}$ Thesis, Eindhoven University of Technology, Eindhoven.

Stoop, P.M.P, Bertrand, M.W.J (1997), "Performance prediction and diagnosis in two production departments”, Integrated Manufacturing Systems , Vol. 8, No.2, pp. 103-109.

Wettstein, T and Kueng, P (2002), “A Maturity Model for Performance Measure Systems”, in C. Brebbia and P. Pascola (eds): Management Information Systems, WIP Press.

Wisner, J.D., and Fawcett, S.E. (1991), "Link firm strategy to operating decisions through performance measurement”, Production and Inventory management Journal, Third Quarter, pp. 5-11. 


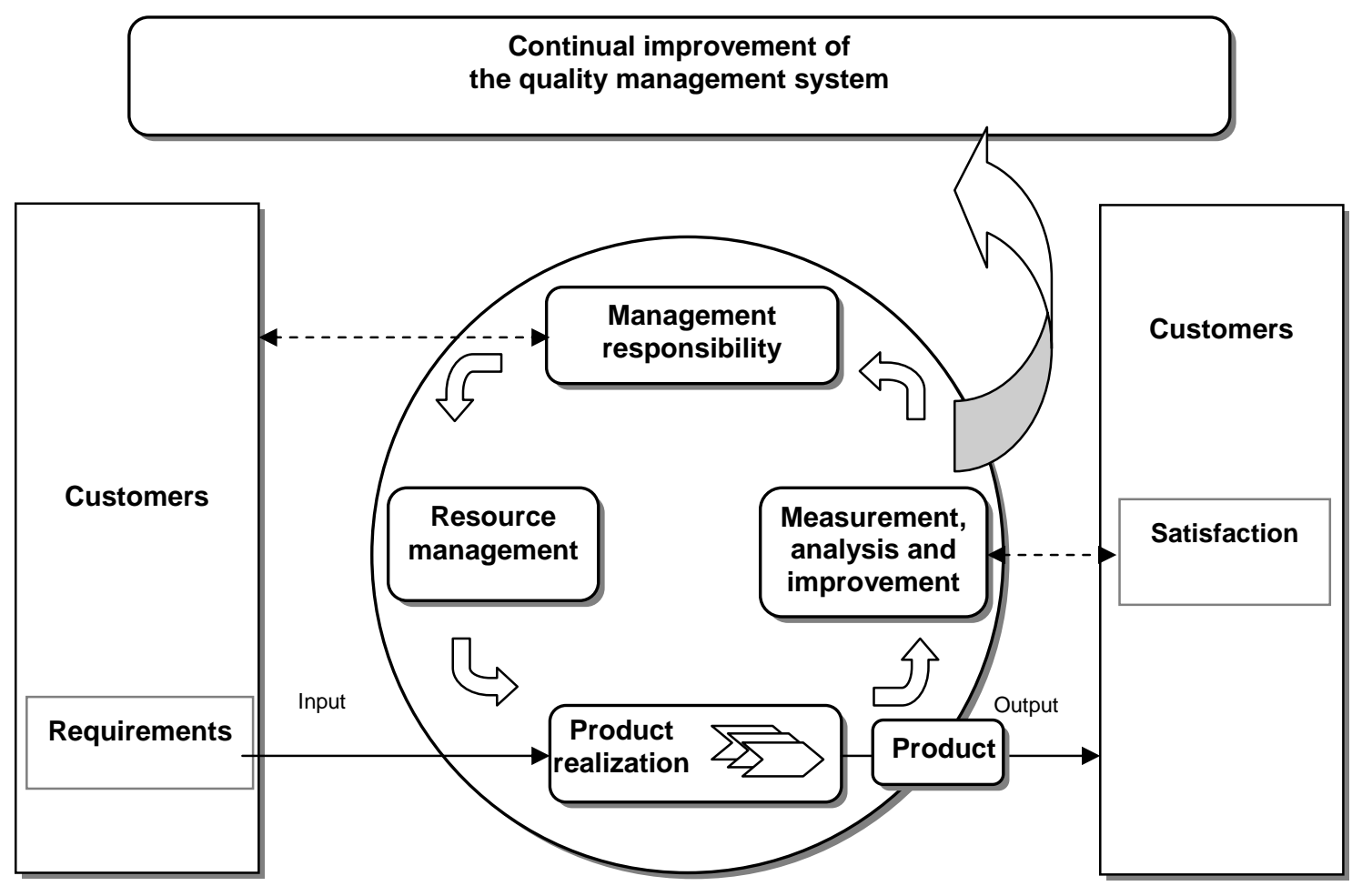

Figure 1. The ISO 9000:2000 Model 


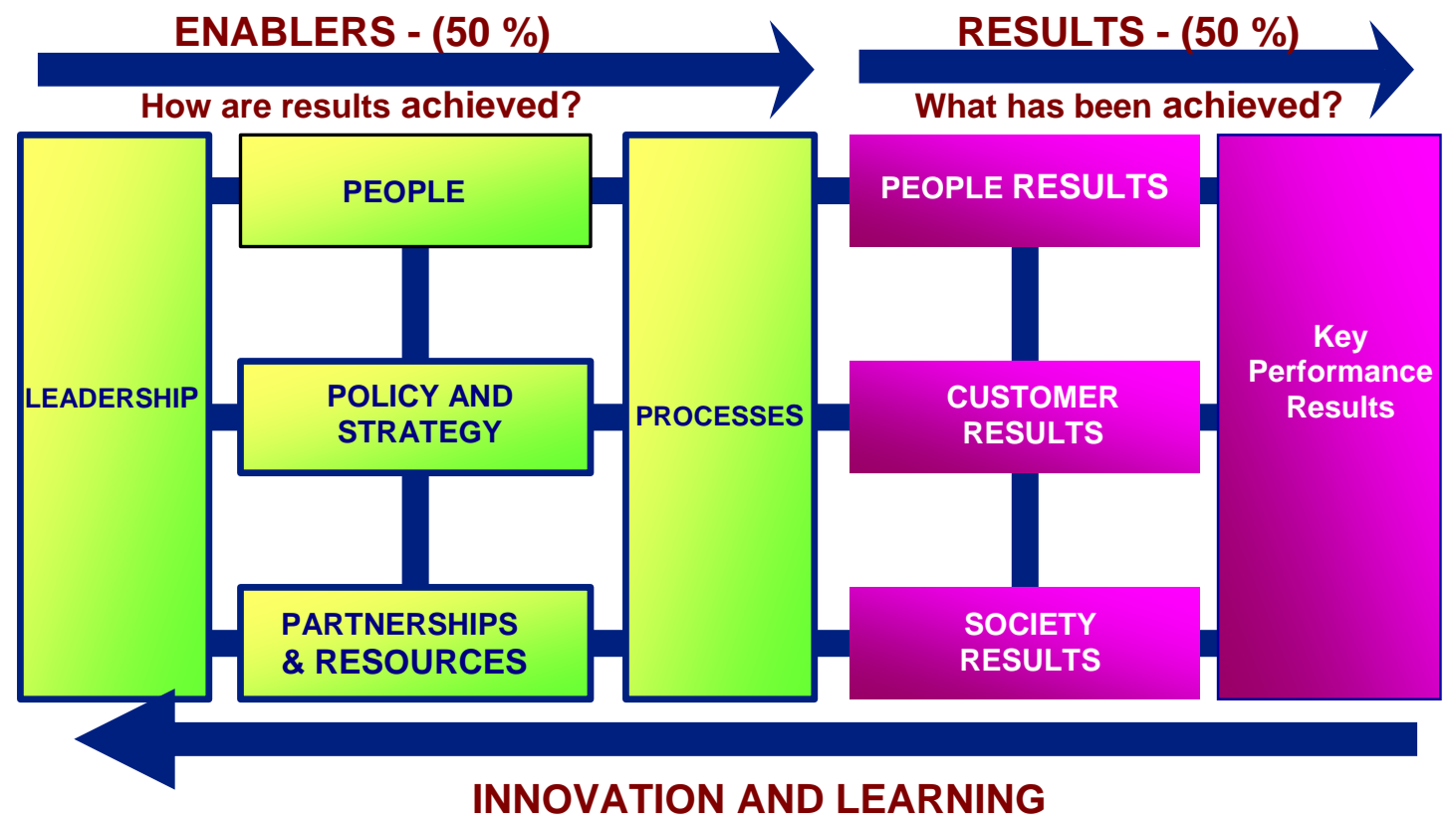

Figure 2. The EFQM Excellence Model 


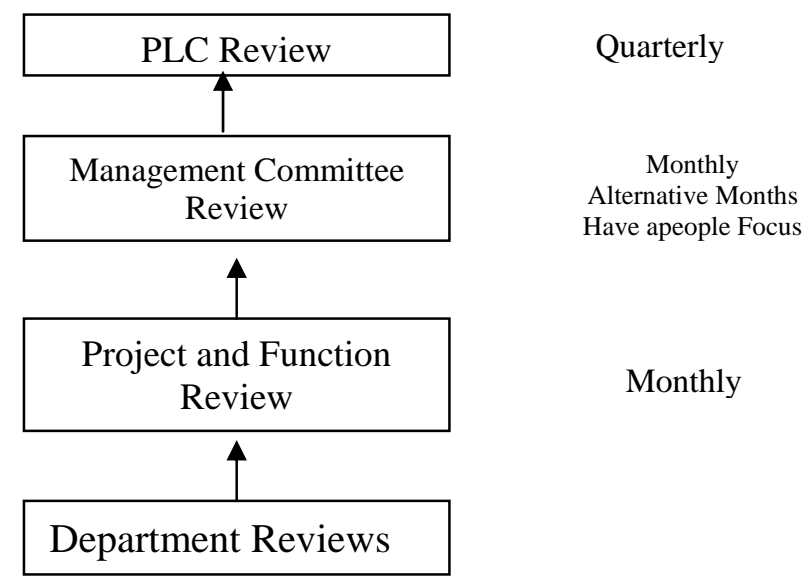

Figure 3. Levels of review in BAE 


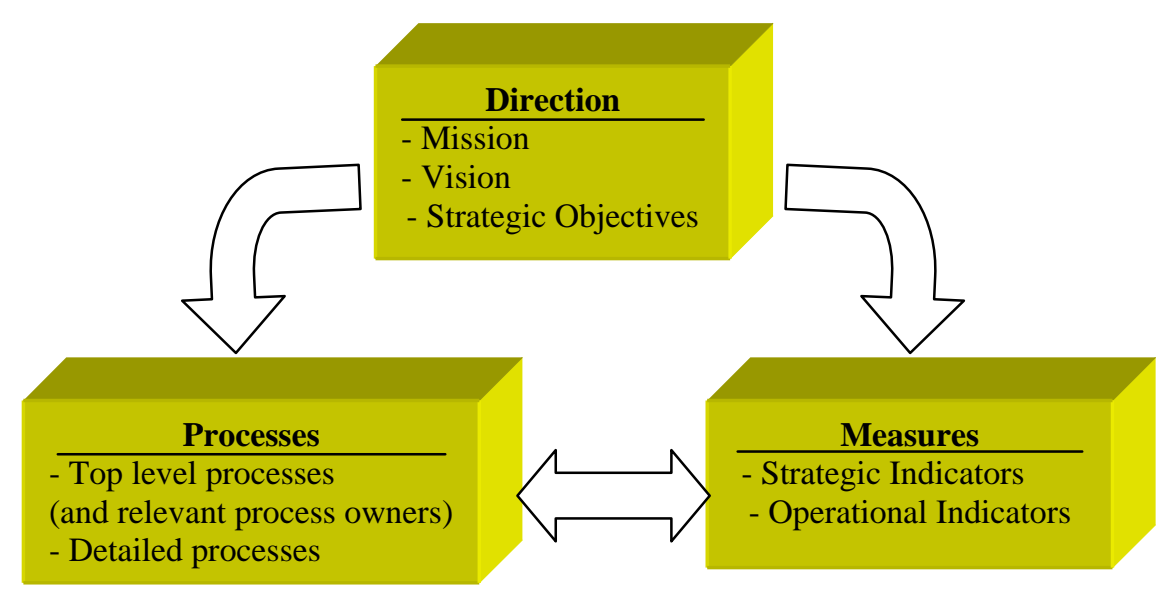

Figure 4. Generic PMS design approach

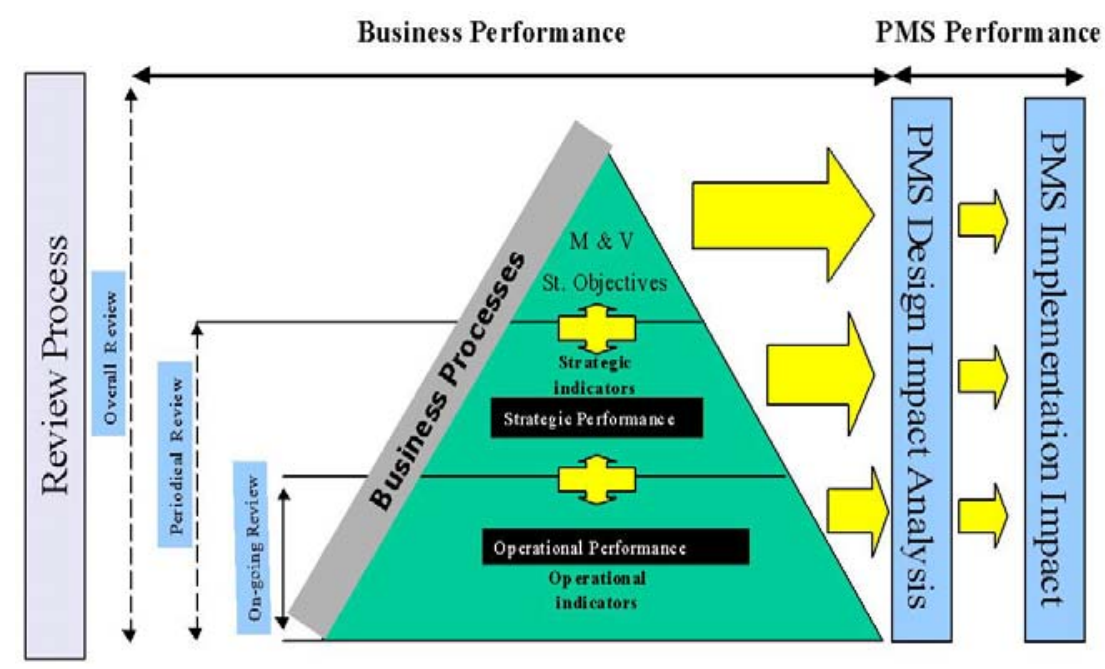

Figure 5. PMS Review Framework 


\begin{tabular}{|l|c|c|c|}
\hline ATTRIBUTES & $\begin{array}{c}\text { On-going } \\
\text { Review }\end{array}$ & Periodic Review & $\begin{array}{l}\text { Overall } \\
\text { Review }\end{array}$ \\
\hline Input & Operational data & Operational + Strategic & All levels \\
\hline Output & $\begin{array}{c}\text { Input(PR + Action } \\
\text { Plan) }\end{array}$ & Input(OR + Action Plan) & Action Plan \\
\hline Frequency & Regular & $1-3$ monthly & Annually \\
\hline Tools & $\begin{array}{c}\text { See Procedure } \\
\text { section }\end{array}$ & See Procedure section & $\begin{array}{c}\text { See Procedure } \\
\text { section }\end{array}$ \\
\hline Scope & $\begin{array}{c}\text { Process Related } \\
\text { Indicator Review } \\
\text { at Operational } \\
\text { Level }\end{array}$ & $\begin{array}{c}\text { Process Related } \\
\text { Indicator Review at } \\
\text { Strategic Level }\end{array}$ & PMS \\
\hline
\end{tabular}

Figure 6. Review Card (PR: Periodic Review; OR: Overall Review) 


$\begin{array}{ll}\begin{array}{l}\text { Performance measures should be derived from } \\ \text { the company's strategy. }\end{array} & \begin{array}{l}\text { Performance measures should enable/facilitate } \\ \text { benchmarking. }\end{array} \\ \begin{array}{l}\text { The purpose of each performance measure must } \\ \text { be made explicit. }\end{array} & \begin{array}{l}\text { Ratio based performance measures are } \\ \text { preferable to absolute numbers. }\end{array} \\ \begin{array}{l}\text { Data collection and methods of calculating the } \\ \text { Performance criteria should be directly under } \\ \text { level of performance must be made clear. }\end{array} & \begin{array}{l}\text { control of the evaluated organizational unit. } \\ \text { Everyone (customers, employees and managers) } \\ \text { Objective performance criteria are preferable } \\ \text { should be involved in the selection of the } \\ \text { measures. }\end{array} \\ \begin{array}{l}\text { the performance measures that are selected } \\ \text { Then-financial measures should be adopted. } \\ \text { should take account of the organization. }\end{array} & \begin{array}{l}\text { Performance measures should be simple and } \\ \text { easy to use. }\end{array} \\ \begin{array}{l}\text { The process should be easily revisitable }- \\ \text { measures should change as circumstances } \\ \text { change. }\end{array} & \begin{array}{l}\text { feedback. } \\ \text { Performance measures should stimulate } \\ \text { continuous improvement rather than just } \\ \text { monitor. }\end{array}\end{array}$

Table 1. Characteristics of PMS design process and measures 